\title{
w-3 Fatty Acids, Genetic Variants in COX-2 and Prostate Cancer
}

\author{
Adam C. Reese ${ }^{a} \quad$ Vincent Fradet $^{a}$ John S. Witte ${ }^{a-c}$ \\ Departments of a Urology and ${ }^{\mathrm{b}}$ Epidemiology and Biostatistics, and ${ }^{\mathrm{C}}$ Institute for Human Genetics, \\ University of California, San Francisco, Calif., USA
}

\section{Key Words}

Cyclooxygenase $2 \cdot$ Diet $\cdot$ Gene $\cdot$ Genetic variation . $\omega-3$ fatty acids $\cdot$ Polyunsaturated fatty acids $\cdot$ Prostatic neoplasms $\cdot$ Single nucleotide polymorphism

\begin{abstract}
Dietary intake of fish and $\omega-3$ polyunsaturated fatty acids ( $\omega-3$ PUFAs) may decrease the risk of prostate cancer development and progression to advanced stage disease. This could reflect the anti-inflammatory effects of PUFAs, possibly through mediation of cyclooxygenase (COX), a key enzyme in fatty acid metabolism and inflammation. Despite promising experimental evidence, epidemiological studies have reported somewhat conflicting results regarding the effects of fish/PUFAs on prostate cancer development and progression. The literature suggests that fish, and particularly long-chain $\omega-3$ PUFAs, may have a more pronounced protective effect on biologically aggressive tumors or on their progression, and less on early steps of carcinogenesis. Moreover, the impact of $\mathrm{LC} \omega-3$ PUFAs may be modified by variation of the COX-2 gene. Overall, results to date support the hypothesis that long-chain $\omega-3$ PUFAs may impact prostate inflammation and carcinogenesis via the COX-2 enzymatic pathway.

Copyright $\odot 2009$ S. Karger AG, Basel
\end{abstract}

\section{Introduction}

Prostate cancer is the most common non-cutaneous malignancy diagnosed in men [1]. In 2009 alone, there are projected to be 191,000 new cases of prostate cancer in the USA, accounting for approximately $25 \%$ of new cancer diagnoses [1]. There are a few well-accepted risk factors for prostate cancer, including family history, African-American ethnicity and particular genetic variants. However, a large percentage of men with prostate cancer do not carry these risk factors, suggesting that there remain important unexplained components to the pathogenesis of disease. Potential environmental risk factors for prostate cancer, including the effects of diet, have shown mixed results. Nevertheless, identifying environmental risk factors for prostate cancer carcinogenesis and studying gene-environment interactions are critically important to advance our understanding of the biology of this disease, and to aid in the development of potential therapeutic interventions.

Equally important is the discovery of factors that predict prostate cancer aggressiveness. This is crucial because despite the ubiquitous nature of the disease, the clinical behavior of prostate cancer is widely heterogeneous. In fact, low-grade, localized cancer that is left un-

\section{KARGER}

\section{(C) 2009 S. Karger AG, Basel}

Fax +41613061234 E-Mail karger@karger.ch www.karger.com www.karger.com/jnn
John S. Witte

Departments of Epidemiology and Biostatistics and Urology

Helen Diller Family Comprehensive Cancer Center, University of California

Diller Bldg, Room 388, 1450 3rd Street, MC 3110

San Francisco, CA 94158-9001 (USA), Tel. +1 415502 6882, E-Mail jwitte@ ucsf.edu 
treated often poses little risk to the patient in terms of symptoms or cancer death; the majority of these patients will ultimately die of other causes [2]. In fact, recent data from CaPSURE, a prostate cancer registry from 40 academic and community-based practices across the USA reported that men diagnosed with very low-risk prostate cancer have only a few percent risk of prostate cancerspecific mortality at 10 years, but have an almost $25 \%$ risk of all-cause mortality [3]. In contrast, high-grade advanced disease is frequently rapidly progressive and fatal. As an example, data from CaPSURE supports a more than $20 \%$ prostate cancer-specific mortality at 10 years for the most aggressive forms of prostate cancer. Despite advances in treatment strategies, prostate cancer remains the second most common cause of cancer-related mortality in the USA, surpassed only by lung cancer [1].

Due to the adoption of widespread PSA screening in the USA in the early 1990's, there has been a significant stage migration, with the majority of tumors in the modern era diagnosed at an early, clinically localized stage [4]. Although most of these tumors could be treated successfully, today's most popular treatment modalities - surgery and radiation therapy - are associated with substantial long-term side effects including erectile dysfunction and urinary incontinence [5]. Thus, the focus of clinical research in recent years has shifted towards identifying those patients with aggressive disease who are at risk for progression, metastases and death and thus warrant definitive treatment despite the associated side effects. Similarly, a growing body of basic research and observational studies are focusing on identifying environmental and genetic factors that predispose to advanced disease.

\section{Role of Inflammation in Carcinogenesis}

Chronic inflammation has been implicated as a causative factor in a wide range of malignancies, including lung, colorectal, pancreatic, bladder and hepatocellular carcinomas [6]. In fact, inflammation is thought to play a role in the causation of approximately $20 \%$ of all human cancers [7]. Increasing evidence supports the role of prostatic inflammation as a risk factor for both development and progression of prostate cancer. It is hypothesized that pro-inflammatory mediators within the prostate can lead to a state of chronic inflammation, resulting in lesions of proliferative inflammatory atrophy that may transition to prostatic intraepithelial neoplasia and eventually adenocarcinoma [7]. Several sources of inflammation may influence the risk of prostate cancer, including dietary
[8], genitourinary bacterial $[9,10]$ and viral $[11]$ infections, and intraprostatic urine reflux $[12,13]$. With regard to diet, a number of nutritional factors may reduce the risk and progression of prostate cancer through antioxidant and anti-inflammatory effects [8]. These include $\omega-3$ polyunsaturated fatty acids (PUFAs), fish, selenium, vitamins $\mathrm{D}$ and $\mathrm{E}$, and lycopene [8].

PUFAs are classified according to their molecular configuration: $\omega-3$ or $\omega-6$. The pro-inflammatory $\omega-6$ PUFAs, such as linoleic acid and arachidonic acid, are metabolized through the cyclooxygenase (COX) pathway into inflammatory eicosanoids, including prostaglandin $\mathrm{E}_{2}$, which has been linked to carcinogenesis in studies of prostate and other tumors $[14,15]$. In contrast, the antiinflammatory $\omega-3$ PUFAs, such as $\alpha$-linolenic acid (ALA) 18:3, eicosapentaenoic acid (EPA) 20:5, docosahexaenoic acid (DHA) 22:6 and docosapentaenoic acid (DPA) 22:5, exhibit their anti-inflammatory properties by competitively inhibiting the arachidonic acid cascade, mainly at the COX pathway [16]. This inhibition reduces the production of pro-inflammatory prostaglandins derived from arachidonic acid, potentially preventing their carcinogenic effect. The long-chain $\omega-3$ PUFAs (LC $\omega-3$ ), EPA, DPA and DHA, appear to be the most potent inhibitors of the COX inflammatory pathway.

PUFAs appear to be beneficial in the prevention and treatment of numerous disease states, including cardiovascular disease, neurodegenerative disorders and cancer [17]. The anti-neoplastic effect of PUFAs in vitro has been demonstrated in breast, colon, lung, liver, pancreatic and leukemia cell lines [18]. This beneficial effect may be mediated through the anti-inflammatory properties of PUFAs, or their modulation of cytokine production.

Foods rich in $\omega-3$ PUFAs include canola and linseed oil, as well as various fish, including herring, salmon, trout, tuna and cod [19]. In the typical Western diet, the main sources of LC $\omega-3$ PUFAs are dark fish and shellfish. The actual LC $\omega-3$ content varies according to fish type; however, these fatty fish are often recommended as an important component of a healthy diet. Epidemiologic studies investigating cancer risk in populations with increased intake of these PUFA-rich foods have been somewhat equivocal. Although some have replicated the promising results of the in-vitro studies, many have found no beneficial effect of PUFAs on the incidence of various malignancies [20]. Investigators have hypothesized that the lack of an anti-neoplastic effect of PUFAs in these studies may be due to an inability to accurately quantify PUFA intake from diet and the potential contamination of PUFA-rich foods with carcinogenic substances. Thus, 
as the laboratory and epidemiological data is often conflicting, further investigation is needed to clarify the effects of PUFAs on carcinogenesis and disease progression in various malignancies.

\section{Experimental Support for PUFA/COX-2 Involvement in Prostate Cancer}

Multiple lines of evidence suggest that PUFAs play a role in prostate carcinogenesis. This effect appears to be at least partially mediated through the enzyme COX. COX, also known as prostaglandin $\mathrm{H}$ synthase or prostaglandin-endoperoxide synthase, catalyzes the rate-limiting step in the formation of inflammatory prostaglandins. While the first form of the enzyme (COX-1) is involved in production of prostaglandins for cellular housekeeping functions, the second form (COX-2) is inducible and is associated with biologic events such as injury, inflammation and proliferation. As stated above, $\omega-3$ and $\omega-6$ PUFAs are both substrates for COX and directly compete for access to the enzyme. COX metabolism of $\omega-6$ PUFAs results in production of pro-inflammatory prostaglandins; however, this metabolic pathway can be blocked by $\omega-3$ PUFAs.

COX-2 is over-expressed in prostate tumors, and thus is speculated to play a role in prostate carcinogenesis [21]. In a mouse model, inhibition of COX-2 suppressed cell growth and led to regression of existing tumors, potentially through induction of apoptosis or decreased tumor angiogenesis [22]. Non-steroidal anti-inflammatory drugs (NSAIDs) have a well-known anti-inflammatory effect in humans, which is partially mediated by COX inhibition. Several epidemiological studies have preliminarily reported that regular NSAID use may in fact decrease the risk of developing prostate cancer in humans [23-25]. Experimental studies in humans have also shown that 3 months of a low-fat, fish-oil-supplemented diet decreased COX-2 expression in prostatic tissue in 4 of 7 men with untreated prostate cancer [26].

Numerous animal studies have demonstrated that adjusting the ratio of $\omega-3$ to $\omega-6$ PUFAs in the diet can alter the behavior of prostate tumors, an effect that appears to be partially mediated through COX-2. In studies of athymic mice with implanted prostate tumors, those mice fed an $\omega-3$ versus an $\omega-6$ PUFA diet exhibited a decreased expression of the inducible pro-inflammatory COX-2 enzyme in tumor cells, as well as decreased tumor cell proliferation and increased apoptosis [27]. Furthermore, $\omega-3$ PUFA fed mice were found to have a decreased

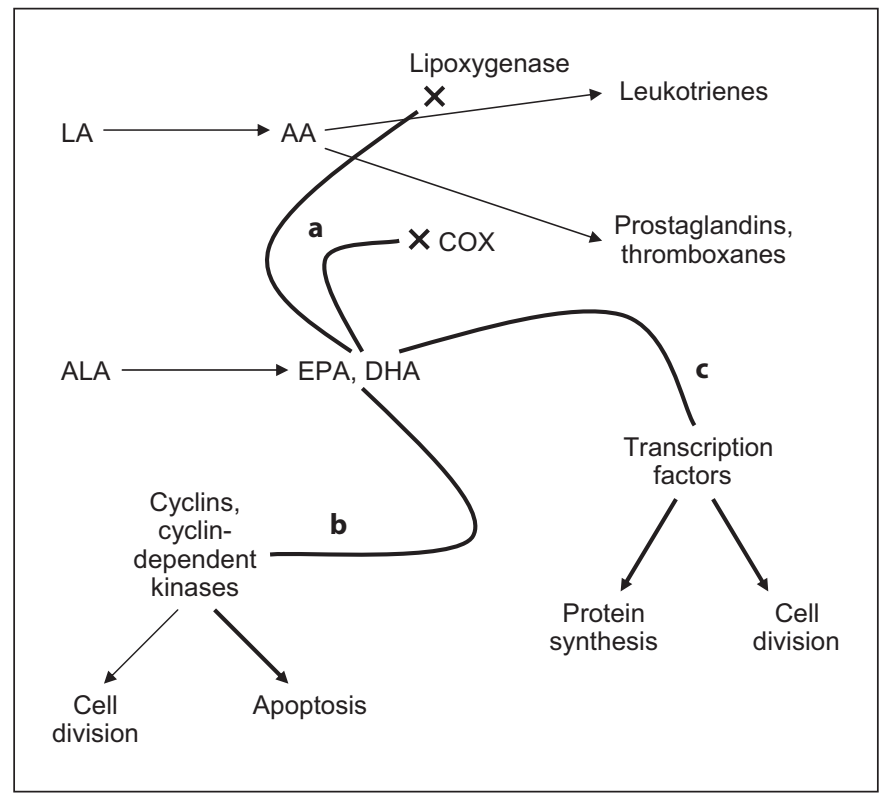

Fig. 1. Simplified schematic illustrating potential mechanisms through which $\omega-3$ PUFAs may exert anti-neoplastic effects. a The $\omega-3$ PUFAs EPA and DHA inihibit activity of COX and lipoxygenase enzymes, thus decreasing production of proinflammatory leukotrienes, prostaglandins and thromboxanes. b $\omega-3$ PUFAs alter activity of cyclins and cyclin-dependent kinases, preferentially shifting cells towards apoptosis. c $\omega-3$ PUFAs alter production and activity of various transcription factors, thus influencing protein production and cell division. AA = Arachidonic acid; $\mathrm{LA}=$ linoleic acid.

rate of prostate cancer recurrence after surgical excision of their tumors (mimicking radical prostatectomy) [27, 28]. It was hypothesized these effects were due to an increased relative concentration of $\omega-3$ PUFAs, leading to a greater degree of COX-2 inhibition. Studies of Ptenknockout mice, an immune-competent orthotopic prostate cancer model, showed that a diet rich in $\omega-3$ PUFAs reduces prostate cancer growth, decreases progression and increases survival [29].

Additional animal studies found that mice fed an EPArich diet have higher $\mathrm{LC} \omega-3$ content in implanted prostate tumors, as well as a better response to hormone ablation. This indicates that PUFAs may play a role in preventing progression of prostate cancer to the androgen-independent state, an end-stage of disease for which very few effective treatment options are available [30].

Although the mechanisms through which PUFAs may exert anti-neoplastic effects are not entirely clear, several hypotheses have been proposed [18, 31] (fig. 1). Competitive inhibition of the COX and lipoxygenase enzymes by 
$\omega-3$ PUFAs leads to decreased production of several inflammatory and potentially carcinogenic molecules, including prostaglandins, thromboxanes and leukotrienes. Additionally, $\omega-3$ PUFAs may modulate the activity of cyclins and cyclin-dependent protein kinases in tumor cells, thus shifting the balance away from cell division and towards apoptosis. Finally, $\omega-3$ PUFAs have been shown to alter the expression of nuclear factor-kappaB, peroxisome proliferator-activated receptor $\gamma$ and retinoid $\mathrm{X}$ receptors, and other transcription factors in vitro [32]. These cellular agents have been implicated in prostate cancer carcinogenesis, and may represent an alternative pathway through which $\omega-3$ PUFAs exhibit antineoplastic activity.

\section{Epidemiological Findings}

\section{PUFAs and Risk of Prostate Cancer}

Epidemiological studies investigating associations between fish/PUFA intake and the development of prostate cancer have given equivocal findings. Of 26 cohort and case-control studies investigating fish/PUFA intake and incidence of prostate cancer, 11 reported inverse association [33-43], 7 positive association [44-50] and 8 showed no association [51-58] (tables 1,2). If one looks only at the 15 cohort studies (table 1), again the results are widely conflicting, with 6 studies suggesting a protective effect of fish/PUFAs [33-38], 3 reporting a harmful effect [4446] and 6 showing no association [51-56].

Overall fish intake, but not the intake of individual PUFAs, has been most consistently inversely associated with prostate carcinogenesis. Although several studies showed no correlation $[37,51,52,54]$, at least 6 studies reported either a trend or a definite association between fish intake and a decreased risk of prostate cancer $[33,34$, $39-41,43$ ]. Terry et al. [34] studied a population of 6,272 Swedish men who were followed prospectively for the development of prostate cancer, and found that those men who ate no fish had a 2- to 3 -fold increased risk of cancer compared to those who ate moderate or high amounts of fish. Two case-control studies reported on separate populations of Canadian men, and both found a statistically significant inverse association between fish intake and the incidence of prostate cancer [39, 40], as did Hedelin et al. [43] in a Swedish study. Collectively, these data support a protective effect of fish, which could potentially be mediated through $\omega-3$ fatty acids, probably more specifically through LC $\omega-3$ (EPA + DHA).
Interestingly, however, most studies specifically investigating the overall effects of $\omega-3$ PUFA intake have shown no correlation with prostate cancer risk. Park et al. [37] reported on a large prospective cohort of 82,483 men in the USA and found a trend towards a decreased risk of prostate cancer with $\omega-3$ PUFA intake, although this effect was largely limited to Latino and white men. Two smaller cohort studies, however, found no association between $\omega-3$ PUFA intake and prostate cancer [51, 56].

Several authors have reported on associations between individual $\omega-3$ PUFAs (ALA, DHA, EPA) and prostate cancer, and again reached largely equivocal results [35, $37,38,42,46,50,53,56-58]$. Although a number of studies reported a negative association between ALA intake and prostate cancer [35, 37, 42], both Giovannucci et al. [46] and Ramon et al. [50] actually found an increased risk of disease with increasing ALA intake. ALA content is quite high in both red meat and animal fat, which have been implicated as causative factors for prostate cancer [59], possibly due to increasing the production of free radicals [45]. Although one relatively large cohort study reported a negative association between DHA/EPA intake and prostate cancer [38], multiple other studies found no association [35, 37, 56, 58].

Finally, most studies found no association between $\omega-6$ PUFA intake and prostate cancer $[36,37,50,56]$. However, there is a suggestion of decreased risk of disease with increasing intake of linoleic acid, the most prevalent w-6 PUFA. Two cohort studies, from the Netherlands [35] and Finland [36], reported a non-significant trend towards a decreased risk with linoleic acid intake, whereas an Italian case-control study found statistically significant inverse associations [42]. This effect may be mediated through the preferential intake of foods rich in linoleic acid over those high in saturated fats, as occurs with the substitution of margarine for butter.

\section{PUFAs and Risk of Advanced Prostate Cancer}

Whereas the literature reports widely variable effects of fish/PUFA intake on prostate cancer incidence, there is stronger data supporting the ability of these foods to decrease the risk of advanced stage disease, metastases and death (tables 1,2). Augustsson et al. [33] reported on a large prospective cohort from the US Health Professionals Follow-Up Study and found that men who ate fish more than 3 times per week were approximately half as likely to develop metastatic cancer as those who ate fish less than twice per month. Three additional cohort studies reported significantly reduced rates of prostate can- 
Table 1. Summary of published cohort studies

\begin{tabular}{|c|c|c|c|c|c|c|c|}
\hline Author, year & Country & $\begin{array}{l}\text { Study size } \\
\mathrm{n}\end{array}$ & $\begin{array}{l}\text { Cases } \\
\mathrm{n}\end{array}$ & PUFA studied & $\begin{array}{l}\text { Effect on overall CaP } \\
\text { incidence }\end{array}$ & $\begin{array}{l}\text { Effect on incidence of } \\
\text { advanced } \mathrm{CaP}\end{array}$ & Ref. \\
\hline Giovannucci, 1993 & USA & 47,855 & 300 & LA, ALA & $\begin{array}{l}\text { non-significant positive } \\
\text { association with ALA }\end{array}$ & $\begin{array}{l}\text { ALA positively associated with } \\
\text { extra-prostatic or metastatic disease }\end{array}$ & 45 \\
\hline Veierod, 1997 & Norway & 25,708 & 72 & all PUFAs & no association & not studied & 55 \\
\hline Schuurman, 1999 & Netherlands & 58,279 & 642 & fish intake & no association & no association & 54 \\
\hline Schuurman, 1999 & Netherlands & 58,279 & 642 & $\begin{array}{l}\text { all PUFAs, LA, ALA, } \\
\text { DHA, EPA }\end{array}$ & $\begin{array}{l}\text { non-significant negative } \\
\text { association only with ALA } \\
\text { and LA }\end{array}$ & no association & 35 \\
\hline Terry, 2001 & Sweden & 6,272 & 466 & fish intake & $\begin{array}{l}\text { negative association with } \\
\text { fish intake }\end{array}$ & $\begin{array}{l}\text { fish intake negatively associated } \\
\text { with mortality }\end{array}$ & 34 \\
\hline Augustsson, 2003 & USA & 47,882 & 2,482 & fish intake & $\begin{array}{l}\text { non-significant negative } \\
\text { association with fish intake }\end{array}$ & $\begin{array}{l}\text { fish intake negatively associated } \\
\text { with metastatic disease }\end{array}$ & 33 \\
\hline Allen, 2004 & Japan & 18,115 & 196 & fish intake & $\begin{array}{l}\text { positive association with } \\
\text { fish intake }\end{array}$ & not studied & 44 \\
\hline Laaksonen, 2004 & Finland & 2,002 & 46 & $\begin{array}{l}\text { all PUFAs, } \omega-6 \\
\text { PUFAs, LA }\end{array}$ & $\begin{array}{l}\text { negative association with } \\
\text { PUFAs and LA }\end{array}$ & not studied & 36 \\
\hline Leitzmann, 2004 & USA & 47,866 & 2,965 & LA, ALA, EPA, DHA & $\begin{array}{l}\text { negative association only } \\
\text { with EPA and DHA }\end{array}$ & $\begin{array}{l}\text { positive association with ALA, } \\
\text { negative association with EPA and } \\
\text { DHA in predicting extra-prostatic, } \\
\text { metastatic or fatal tumors }\end{array}$ & 38 \\
\hline Koralek, 2006 & USA & 29,592 & 1,898 & ALA & no association with ALA & no association & 53 \\
\hline Park, 2007 & USA & 82,483 & 4,404 & $\begin{array}{l}\text { all PUFAs, } \omega-6 \\
\text { PUFAs, } \omega-3 \text { PUFAs, } \\
\text { ALA, EPA, DHA }\end{array}$ & $\begin{array}{l}\text { non-significant negative as- } \\
\text { sociation with } \omega-3 \text { PUFA } \\
\text { and ALA. Association stron- } \\
\text { ger in Latinos and whites }\end{array}$ & $\begin{array}{l}\text { non-significant negative association } \\
\text { between } \omega-3 \text { PUFA/ALA and } \\
\text { non-localized or high-grade disease }\end{array}$ & 37 \\
\hline Wallstrom, 2007 & Sweden & 10,564 & 817 & $\begin{array}{l}\text { all PUFAs, LA, ALA, } \\
\text { EPA, DHA }\end{array}$ & $\begin{array}{l}\text { positive association only } \\
\text { with EPA and DHA }\end{array}$ & no association & 56 \\
\hline Giovannucci, 2007 & USA & 51,529 & 3,544 & ALA & $\begin{array}{l}\text { positive association with } \\
\text { ALA }\end{array}$ & $\begin{array}{l}\text { ALA positively associated with } \\
\text { mortality }\end{array}$ & 46 \\
\hline Crowe, 2008 & $\begin{array}{l}\text { several } \\
\text { European } \\
\text { nations }\end{array}$ & 142,520 & 2,727 & $\begin{array}{l}\text { all PUFAs, fat from } \\
\text { fish }\end{array}$ & $\begin{array}{l}\text { no association with PUFAs } \\
\text { or fish }\end{array}$ & $\begin{array}{l}\text { inverse association between PUFAs } \\
\text { and high-grade (but not advanced } \\
\text { stage) disease }\end{array}$ & 52 \\
\hline Chavarro, 2008 & USA & 20,167 & 2,161 & $\begin{array}{l}\text { fish intake, } \omega-3 \text { PUFA } \\
\text { fish }\end{array}$ & $\begin{array}{l}\text { no association with fish } \\
\text { or } \omega-3 \text { PUFA fish }\end{array}$ & $\begin{array}{l}\text { fish and } \omega-3 \text { PUFA intake associated } \\
\text { with decreased mortality }\end{array}$ & 51 \\
\hline Pham, 2009 & Japan & 5,589 & \multicolumn{2}{|c|}{21 deaths fish intake } & not studied & $\begin{array}{l}\text { fish intake negatively associated } \\
\text { with mortality }\end{array}$ & 60 \\
\hline
\end{tabular}

$\mathrm{CaP}=$ Prostate cancer; $\mathrm{LA}=$ linoleic acid.

cer-specific mortality in those men consuming larger quantities of fish $[34,51,60]$.

Identification of the actual nutritional components of fish that are responsible for this decrease in advancedstage disease and mortality, however, is complicated. Prior reports have hypothesized that $\omega-3$ PUFAs are the protective factor, but there is only modest data in the literature to support this claim. Whereas several studies have shown at least a trend towards decreased risk of advanced disease or death with $\omega-3$ PUFA intake $[37,51]$, most studies investigating individual $\omega-3$ PUFAs (ALA, EPA, DHA) have not replicated this finding $[35,37,53$, $56-58,61]$. Of 5 reports investigating the effects of EPA and DHA on advanced disease, only 1 cohort study reported an inverse association [38], whereas the remainder found no association $[35,37,56,58]$. Contrary to many 
Table 2. Summary of published case-control studies

\begin{tabular}{|c|c|c|c|c|c|c|c|}
\hline Author, year & Country & $\begin{array}{l}\text { Cases } \\
\mathrm{n}\end{array}$ & $\begin{array}{l}\text { Controls } \\
\mathrm{n}\end{array}$ & $\begin{array}{l}\text { PUFA } \\
\text { studied }\end{array}$ & $\begin{array}{l}\text { Effect on overall } \\
\mathrm{CaP} \text { incidence }\end{array}$ & $\begin{array}{l}\text { Effect on incidence } \\
\text { of advanced } \mathrm{CaP}\end{array}$ & Ref. \\
\hline Rohan, 1995 & Canada & 207 & 207 & all PUFAs & $\begin{array}{l}\text { non-significant positive } \\
\text { association with PUFAs }\end{array}$ & not studied & 48 \\
\hline Andersson, 1996 & Sweden & 526 & 536 & all PUFAs, LA, ALA & no association & no association & 57 \\
\hline Ghadirian, 1996 & Canada & 232 & 231 & all PUFAs & $\begin{array}{l}\text { non-significant positive } \\
\text { association with PUFAs }\end{array}$ & not studied & 47 \\
\hline Bairati, 1998 & Canada & 142 & 242 & all PUFAs, LA, ALA & not studied & $\begin{array}{l}\text { non-significant negative association } \\
\text { between only PUFAs and LA and risk } \\
\text { of non-localized disease }\end{array}$ & 61 \\
\hline Fernandez, 1999 & Italy & 127 & 7,990 & fish intake & $\begin{array}{l}\text { non-significant negative } \\
\text { association with fish intake }\end{array}$ & not studied & 41 \\
\hline Tzonou, 1999 & Greece & 320 & 246 & all PUFAs & $\begin{array}{l}\text { positive association with } \\
\text { PUFAs }\end{array}$ & not studied & 49 \\
\hline Meyer, 1999 & Canada & 32 & 382 & all PUFAs & not studied & no association with mortality & 64 \\
\hline De Stéfani, 2000 & Uruguay & 217 & 431 & LA, ALA & not studied & $\begin{array}{l}\text { ALA associated with increased risk of } \\
\text { extra-prostatic or metastatic tumors }\end{array}$ & 62 \\
\hline Ramon, 2000 & Spain & 217 & 434 & $\begin{array}{l}\text { all PUFAs, } \omega-6 \text { PUFAs, } \\
\text { ALA }\end{array}$ & $\begin{array}{l}\text { positive association only } \\
\text { with ALA }\end{array}$ & no association with mortality & 50 \\
\hline Kristal, 2002 & USA & 605 & 592 & all PUFAs, EPA+DHA & No association & no association & 58 \\
\hline Bidoli, 2005 & Italy & 1,294 & 1,451 & all PUFAs, LA, ALA & $\begin{array}{l}\text { Negative association of all } \\
\text { PUFAs, ALA, and LA }\end{array}$ & not studied & 42 \\
\hline Hedelin, 2007 & Sweden & 1,499 & 1,130 & $\begin{array}{l}\text { fish intake, } \omega-6 \text { PUFAs, } \\
\omega-3 \text { PUFAs, LA, ALA, } \\
\text { EPA+DHA }\end{array}$ & $\begin{array}{l}\text { negative association with } \\
\text { fish intake; positive asso- } \\
\text { ciation with } \omega-6 \text { PUFAs } \\
\text { and LA }\end{array}$ & not studied & 43 \\
\hline Amin, 2008 & Canada & 386 & 917 & fish intake & $\begin{array}{l}\text { negative association with } \\
\text { fish intake }\end{array}$ & no association & 39 \\
\hline Mina, 2008 & Canada & 1,534 & 1,607 & fish intake & $\begin{array}{l}\text { negative association with } \\
\text { fish intake }\end{array}$ & not studied & 40 \\
\hline Fradet, 2009 & USA & 506 & 506 & $\begin{array}{l}\text { LA, ALA, EPA, DPA, } \\
\text { LC } \omega-3 \text { PUFAs }\end{array}$ & not studied & $\begin{array}{l}\text { negative association between } \mathrm{LC} \omega-3 \\
\text { PUFAs and aggressive } \mathrm{CaP}\end{array}$ & 63 \\
\hline
\end{tabular}

$\mathrm{CaP}=$ Prostate cancer LA = linoleic acid.

hypotheses, increasing ALA intake has actually been shown to increase the risk of advanced-stage disease in several studies. Two separate prospective analyses of the US Health Professionals Follow-Up Study first reported increased rates of advanced disease [38], and then death [46], with increasing ALA intake. A separate case-control study of patients with extra-prostatic or metastatic cancer in Uruguay found a positive association between ALA and these adverse outcomes [62].

In our own research, we found strong inverse associations between increasing intake of LC $\omega-3$ EPA, DPA and DHA and aggressive prostate cancer [63]. The decreased risk followed a clear dose-response pattern across increasing levels of LC $\omega-3$ intake, whereby men in the highest quartile of consumption had less than half the risk of aggressive disease in comparison to men in the lowest quartile. Similar inverse associations were observed for increasing intake of dark fish and shellfish, the 2 main sources of LC $\omega-3$.

\section{Epidemiological Studies}

The above discussion illustrates the significant controversy in the literature regarding the effects of fish/ PUFA intake on the incidence of prostate cancer and the 
progression to advanced-stage disease. The explanation for the markedly heterogeneous results remains unclear, but a careful examination of the methods underlying the published studies provides important insights.

In many of the studies reporting no association between PUFAs and prostate cancer incidence, the fish type was not differentiated $[37,54]$ or individual PUFAs were not distinguished, but rather evaluated overall $[35,55$, 64]. Supported primarily by a trend from the more recent literature, LC $\omega-3$ - and fish rich in these nutrients - appear protective, while other $\omega-3$ PUFAs or $\omega-6$ PUFAs may be deleterious for prostate cancer. Not all PUFAs, and even not all $\omega-3$ PUFAs, may be equal regarding their effect on prostate cancer, and it appears important to study each nutrient's effect separately.

Additionally, in many studies the exposure was defined with a single survey, with follow-up 20-30 years later, during which time dietary patterns may have changed significantly. For example, in Japan there is evidence that dietary habits have changed significantly over the past decades [65], during which time 1 study showing a positive association between fish intake and prostate cancer was conducted [44].

These potential measurement issues may explain the absence of association sometimes observed. Prospective studies where exposure is reassessed periodically, such as the Health Professional Follow-up Study [33, 38], provide better measures of adult dietary intake and changing dietary factors, and have shown a protective effect of fish intake on prostate cancer incidence. Moreover, some negative studies were conducted on cohorts with short follow-up, which might be problematic for prostate cancer since it is a relatively latent disease that generally occurs later in life $[45,46]$.

The level of $\omega-3 /$ fish intake may affect study results. A very low level of dietary $\omega-3 /$ fish may make it difficult to detect associations due to the narrow range of exposure variation. In fact, some studies observing no association were conducted in populations where $\omega-3 /$ fish levels were substantially lower $[35,37,54]$ than in studies where significant inverse associations were observed, such as the Health Professionals Follow-Up Study [33]. Of the studies reporting a positive association between LC $\omega-3 /$ fish intake and prostate cancer risk, 2 were undertaken in populations with much higher fish intake than our study - Sweden [56] and Japan [44] - and they did not differentiate type of fish consumed. Although some have proposed that the effect of LC $\omega-3$ PUFAs may convert from protective to harmful when consumed in excessive quantities, there is no data to support this hypothesis, not even from studies of cardiovascular diseases, where modeling of effect by level of intake has been proposed [66].

Another possible explanation is that the positive association could be attributed to environmental toxins, such as polychlorinated biphenyls or methylmercury compounds contained in fish. These toxins are known to disrupt the androgen/estrogen balance, and exposure has been linked to the risk of prostate cancer in prior reports $[67,68]$. Certainly, further investigation is needed to clarify this potentially harmful interaction.

The literature suggests that fish/LC $\omega-3$ may have a more pronounced effect on biologically aggressive tumors or on their progression, and less on carcinogenesis of more benign or earlier stage tumors often detected by screening. This appears to be true across several different geographic areas with significantly varying baseline population levels of fish and LC $\omega-3$ intake $[33-35,38,44,54$, 56]. The beneficial effect requires further investigation, as clarification and exploitation of this pathway could potentially decrease rates of progression, metastases, and death in men with early-stage, low-grade disease.

Finally, the somewhat inconsistent findings in the literature might reflect the distinct heterogeneity of prostate cancer. The potential protective effect of fish and LC $\omega-3$ appears strongest for aggressive disease, which may exhibit different biological behavior than low-stage, lowgrade disease. Even within individual studies, disease heterogeneity could potentially mask a beneficial effect of PUFAs. Those studies investigating prostate cancer incidence often included patients with a wide range of disease, from clinically localized tumors detected through screening, to those patients presenting with extraprostatic or metastatic disease. Thus, the beneficial effects of PUFAs on one stage of disease could potentially be masked by their lack of effect on another. Additionally, tumors are now often detected through PSA screening, whereas earlier studies were conducted prior to the PSA era, or in countries where PSA screening is not routinely practiced. Given the stage migration that has resulted from widespread PSA screening [4], one would expect a larger percentage of early-stage, low-grade tumors in the most recent studies. Since it appears that the protective effect of PUFAs is greater for advanced stage tumors, stage migration towards early-stage disease may bias study results towards finding no associations between PUFAs and incidence of disease, further contributing to the widely conflicting conclusions in the published literature. 


\section{Modification by COX-2 Genotype}

Candidate gene studies have found that sequence variants in the COX-2 gene influence the risk of prostate cancer [69-71]. Thus, effect modification by COX-2 genotype was hypothesized as a possible explanation for the wide variation in reported associations between $\omega-3$ PUFA intake and prostate cancer. A recent study of Swedish men confirmed this interaction, finding that frequent consumption of fatty fish - a proxy for long-chain $\omega-3$ PUFAs - was inversely associated with prostate cancer risk $(\mathrm{OR}=0.57$; 95\% CI 0.43-0.76) [43]. Moreover, this effect was modified by the rs5275 (+6364 A>G) single nucleotide polymorphism (SNP) in COX-2, whereby only men carrying the variant allele maintained a strong inverse association between fatty fish intake and prostate cancer. This suggests that the potential protective effect of long-chain PUFAs on prostate cancer may be modified by $C O X-2$.

In our research, we found that the $\mathrm{LC} \omega-3$ inverse association was stronger in carriers of the variant $\mathrm{COX}-2$ SNP rs4648310 (+8897 A>G) [63]. Interestingly, men with the variant genotype (AG or GG) and low intake of LC $\omega-3$ had a much higher risk of aggressive disease than men with the variant genotype but a high intake of LC $\omega-3$. This suggests that while carriers of the variant SNP had an overall increased risk of aggressive prostate cancer, this deleterious effect was found only in men consuming low levels of LC $\omega-3$, and the association could be reversed by increasing consumption of LC $\omega-3$. This interaction was similar across individual LC $\omega-3$ (EPA, DPA and DHA) and dark fish (interaction $\mathrm{p}=0.002$, data not shown) - the main source of the PUFAs.

These results are in general agreement with those previously reported in the Swedish study [43]. Although rs4648310 (+8897 A>G) was not genotyped in their study, they found that another COX-2 SNP (rs5275, +6364 A>G) modified the impact of fish intake on prostate cancer (p interaction < 0.01). In particular, Salmon-type fish consumption - a proxy for LC $\omega-3$ intake - was protective only among men carrying the variant rs5275 genotypes ( $\mathrm{p}$ trend $<0.01$ ). We did not observe a similar pattern of interaction with rs5275 in our study ( $p$ interaction $=0.8$ ). SNPs rs4648310 and rs5275 are not in linkage disequilibrium in our population $\left(\mathrm{r}^{2}=0.01\right.$, among whites).

The functional impact of rs5275, an intronic variant, and rs4648310, flanking the $3^{\prime}$ COX-2 gene, on COX-2 activity is not yet known. It is possible that either of these polymorphisms, or another linked variant, may affect function of the COX-2 enzyme. Just as the protective effect of $\omega-3$ PUFAs may be mediated through the COX-2 SNP rs4648310, we have previously shown that variation at a separate COX-2 SNP rs 2745557 alters the ability of NSAIDs to affect risk of disease [70]. Both LC $\omega-3$ and NSAID compete with arachidonic acid for binding to the COX active site, although their downstream effects appear different $[72,73]$. Thus, it could be hypothesized that variation at these COX-2 SNPs alters the enzyme's structure or function, enabling it to preferentially bind LC $\omega-3$, NSAID or other substrates. This changing affinity for various ligands may affect the enzyme's pro-inflammatory function, and thus modify the risk of developing prostate cancer. Collectively, the combined findings of our study [63] and that of the Swedish population [43] support the overall hypothesis that LC $\omega-3$ modifies prostate inflammation through the COX-2 enzymatic pathway.

\section{Summary}

Despite conflicting results in the literature, recent data presents convincing evidence that dietary LC $\omega-3$ are inversely associated with aggressive prostate cancer. This potential protective effect may be modified by genetic variation in COX-2. Interestingly, it appears the deleterious effect of 1 SNP (rs4648310, +8897 A>G) can be reversed by increased LC $\omega-3$ intake. These results support the role of inflammation and COX activity in prostate cancer susceptibility and progression. More clinical and biological studies are needed to decipher the mechanisms through which dietary long-chain $\omega-3$ fatty acids and other factors involved with inflammation, such as $\mathrm{COX}-2$ genotypes, may affect prostate cancer risk and aggressiveness.

\section{Acknowledgments}

This work was supported by the National Institute of Health grants CA88164 and CA94211. V.F. is supported by the McLaughlin dean's grant from Laval University. 


\section{References}

1 Society AC: Cancer Facts and Figures. At- 15 Terry PD, Rohan TE, Wolk A: Intakes of fish lanta, American Cancer Society, 2009.

- Johansson JE, Holmberg L, Johansson S, Bergstrom R, Adami HO: Fifteen-year survival in prostate cancer: a prospective, population-based study in Sweden. JAMA 1997; 277:467-471.

- 3 Cooperberg MR, Broering JM, Carroll PR: Risk assessment for prostate cancer metastasis and mortality at the time of diagnosis. J Natl Cancer Inst 2009;101:878-887.

-4 Jani AB, Vaida F, Hanks G, Asbell S, Sartor O, Moul JW, Roach M 3rd, Brachman D, Kalokhe U, Muller-Runkel R, Ray P, Ignacio L, Awan A, Weichselbaum RR, Vijayakumar $S$ : Changing face and different countenances of prostate cancer: racial and geographic differences in prostate-specific antigen (PSA), stage, and grade trends in the PSA era. Int J Cancer 2001;96:363-371.

5 Wilt TJ, MacDonald R, Rutks I, Shamliyan TA, Taylor BC, Kane RL: Systematic review: comparative effectiveness and harms of treatments for clinically localized prostate cancer. Ann Intern Med 2008;148:435-448.

-6 Coussens LM, Werb Z: Inflammation and cancer. Nature 2002;420:860-867.

7 De Marzo AM, Platz EA, Sutcliffe S, Xu J, Gronberg H, Drake CG, Nakai Y, Isaacs WB, Nelson WG: Inflammation in prostate carcinogenesis. Nat Rev Cancer 2007;7:256-269.

-8 Chan JM, Gann PH, Giovannucci EL: Role of diet in prostate cancer development and progression. J Clin Oncol 2005;23:8152-8160.

$\checkmark 9$ Dennis LK, Dawson DV: Meta-analysis of measures of sexual activity and prostate cancer. Epidemiology 2002;13:72-79.

10 Taylor ML, Mainous AG 3rd, Wells BJ: Prostate cancer and sexually transmitted diseases: a meta-analysis. Fam Med 2005;37:506512 .

- 11 Urisman A, Molinaro RJ, Fischer N, Plummer SJ, Casey G, Klein EA, Malathi K, MagiGalluzzi C, Tubbs RR, Ganem D, Silverman RH, DeRisi JL: Identification of a novel gammaretrovirus in prostate tumors of patients homozygous for R462Q RNA SEL variant. PLoS Pathog 2006;2:e25.

12 Kirby RS, Lowe D, Bultitude MI, Shuttleworth KE: Intra-prostatic urinary reflux: An aetiological factor in abacterial prostatitis. Br J Urol 1982;54:729-731.

13 Persson BE, Sjoman M, Niklasson F, Ronquist G: Uridine, xanthine and urate concentrations in prostatic fluid and seminal plasma of patients with prostatitis. Eur Urol 1991; 19:253-256.

14 Rose DP: Dietary fatty acids and prevention of hormone-responsive cancer. Proc Soc Exp Biol Med 1997;216:224-233. and marine fatty acids and the risks of cancers of the breast and prostate and of other hormone-related cancers: a review of the epidemiologic evidence. Am J Clin Nutr 2003; 77:532-543.

16 McEntee MF, Whelan J: Dietary polyunsaturated fatty acids and colorectal neoplasia. Biomed Pharmacother 2002;56:380-387.

17 Riediger ND, Othman RA, Suh M, Moghadasian MH: A systemic review of the roles of n-3 fatty acids in health and disease. J Am Diet Assoc 2009;109:668-679.

18 Calviello G, Serini S, Piccioni E, Pessina G: Antineoplastic effects of $n-3$ polyunsaturated fatty acids in combination with drugs and radiotherapy: preventive and therapeutic strategies. Nutr Cancer 2009;61:287-301.

19 Russo GL: Dietary n-6 and n-3 polyunsaturated fatty acids: from biochemistry to clinical implications in cardiovascular prevention. Biochem Pharmacol 2009;77:937-946.

20 Hooper L, Thompson RL, Harrison RA, Summerbell CD, Ness AR, Moore HJ, Worthington HV, Durrington PN, Higgins JP, Capps NE, Riemersma RA, Ebrahim SB Davey Smith G: Risks and benefits of omega3 fats for mortality, cardiovascular disease, and cancer: systematic review. BMJ 2006; 332:752-760.

21 Gupta S, Srivastava M, Ahmad N, Bostwick DG, Mukhtar H: Over-expression of cyclooxygenase-2 in human prostate adenocarcinoma. Prostate 2000;42:73-78.

22 Liu XH, Kirschenbaum A, Yao S, Lee R, Holland JF, Levine AC: Inhibition of cyclooxygenase-2 suppresses angiogenesis and the growth of prostate cancer in vivo. J Urol 2000;164:820-825.

23 Nelson JE, Harris RE: Inverse association of prostate cancer and non-steroidal antiinflammatory drugs (NSAIDs): results of a case-control study. Oncol Rep 2000;7:169170.

24 Norrish AE, Jackson RT, McRae CU: Nonsteroidal anti-inflammatory drugs and prostate cancer progression. Int J Cancer 1998;77: 511-515.

- 25 Roberts RO, Jacobson DJ, Girman CJ, Rhodes T, Lieber MM, Jacobsen SJ: A populationbased study of daily nonsteroidal anti-inflammatory drug use and prostate cancer. Mayo Clin Proc 2002;77:219-225.

26 Aronson WJ, Glaspy JA, Reddy ST, Reese D, Heber D, Bagga D: Modulation of omega-3/ omega- 6 polyunsaturated ratios with dietary fish oils in men with prostate cancer. Urology 2001;58:283-288.

27 Kelavkar UP, Hutzley J, Dhir R, Kim P, Allen $\mathrm{KG}, \mathrm{McHugh} \mathrm{K}$ : Prostate tumor growth and recurrence can be modulated by the omega6:omega-3 ratio in diet: athymic mouse xenograft model simulating radical prostatectomy. Neoplasia 2006;8:112-124.
28 Kelavkar UP, Hutzley J, McHugh K, Allen KG, Parwani A: Prostate tumor growth can be modulated by dietarily targeting the 15 lipoxygenase-1 and cyclooxygenase- 2 enzymes. Neoplasia 2009;11:692-699.

29 Berquin IM, Min Y, Wu R, Wu J, Perry D, Cline JM, Thomas MJ, Thornburg T, Kulik G, Smith A, Edwards IJ, D'Agostino R, Zhang $\mathrm{H}, \mathrm{Wu} \mathrm{H}$, Kang JX, Chen YQ: Modulation of prostate cancer genetic risk by omega-3 and omega- 6 fatty acids. J Clin Invest 2007;117: 1866-1875.

-30 McEntee MF, Ziegler C, Reel D, Tomer K, Shoieb A, Ray M, Li X, Neilsen N, Lih FB, O'Rourke D, Whelan J: Dietary n-3 polyunsaturated fatty acids enhance hormone ablation therapy in androgen-dependent prostate cancer. Am J Pathol 2008;173:229-241.

- 31 Larsson SC, Kumlin M, Ingelman-Sundberg M, Wolk A: Dietary long-chain n-3 fatty acids for the prevention of cancer: a review of potential mechanisms. Am J Clin Nutr 2004; 79:935-945.

32 Narayanan NK, Narayanan BA, Reddy BS: A combination of docosahexaenoic acid and celecoxib prevents prostate cancer cell growth in vitro and is associated with modulation of nuclear factor-kappab, and steroid hormone receptors. Int J Oncol 2005;26:785792.

33 Augustsson K, Michaud DS, Rimm EB, Leitzmann MF, Stampfer MJ, Willett WC, Giovannucci E: A prospective study of intake of fish and marine fatty acids and prostate cancer. Cancer Epidemiol Biomarkers Prev 2003; 12:64-67.

- 34 Terry P, Lichtenstein P, Feychting M, Ahlbom A, Wolk A: Fatty fish consumption and risk of prostate cancer. Lancet 2001;357: 1764-1766.

35 Schuurman AG, van den Brandt PA, Dorant E, Brants HA, Goldbohm RA: Association of energy and fat intake with prostate carcinoma risk: results from the Netherlands cohort study. Cancer 1999;86:1019-1027.

36 Laaksonen DE, Laukkanen JA, Niskanen L, Nyyssonen K, Rissanen TH, Voutilainen S, Pukkala E, Hakkarainen A, Salonen JT: Serum linoleic and total polyunsaturated fatty acids in relation to prostate and other cancers: a population-based cohort study. Int J Cancer 2004;111:444-450.

-37 Park SY, Murphy SP, Wilkens LR, Henderson BE, Kolonel LN: Fat and meat intake and prostate cancer risk: The multiethnic cohort study. Int J Cancer 2007;121:1339-1345.

-38 Leitzmann MF, Stampfer MJ, Michaud DS, Augustsson K, Colditz GC, Willett WC, Giovannucci EL: Dietary intake of n-3 and $\mathrm{n}-6$ fatty acids and the risk of prostate cancer. Am J Clin Nutr 2004;80:204-216. 
39 Amin M, Jeyaganth S, Fahmy N, Begin LR, Aronson S, Jacobson S, Tanguay S, Kassouf W, Aprikian A: Dietary habits and prostate cancer detection: a case-control study. Can Urol Assoc J 2008;2:510-515.

$\checkmark 40$ Mina K, Fritschi L, Johnson KC: An inverse association between preserved fish and prostate cancer: results from a population-based case-control study in Canada. Nutr Cancer 2008;60:222-226.

-41 Fernandez E, Chatenoud L, La Vecchia C, Negri E, Franceschi S: Fish consumption and cancer risk. Am J Clin Nutr 1999;70:85-90.

42 Bidoli E, Talamini R, Bosetti C, Negri E, Maruzzi D, Montella M, Franceschi S, La Vecchia C: Macronutrients, fatty acids, cholesterol and prostate cancer risk. Ann Oncol 2005;16:152-157.

43 Hedelin M, Chang ET, Wiklund F, Bellocco $\mathrm{R}$, Klint A, Adolfsson J, Shahedi K, Xu J, Adami HO, Gronberg H, Balter KA: Association of frequent consumption of fatty fish with prostate cancer risk is modified by COX-2 polymorphism. Int J Cancer 2007; 120:398-405

-44 Allen NE, Sauvaget C, Roddam AW, Appleby P, Nagano J, Suzuki G, Key TJ, Koyama K: A prospective study of diet and prostate cancer in Japanese men. Cancer Causes Control 2004;15:911-920.

45 Giovannucci E, Rimm EB, Colditz GA, Stampfer MJ, Ascherio A, Chute CC, Willett WC: A prospective study of dietary fat and risk of prostate cancer. J Natl Cancer Inst 1993;85:1571-1579.

-46 Giovannucci E, Liu Y, Platz EA, Stampfer MJ, Willett WC: Risk factors for prostate cancer incidence and progression in the Health Professionals Follow-up Study. Int J Cancer 2007;121:1571-1578.

$\checkmark 47$ Ghadirian P, Lacroix A, Maisonneuve P, Perret C, Drouin G, Perrault JP, Beland G, Rohan TE, Howe GR: Nutritional factors and prostate cancer: a case-control study of French Canadians in Montreal, Canada. Cancer Causes Control 1996;7:428-436.

-48 Rohan TE, Howe GR, Burch JD, Jain M: Dietary factors and risk of prostate cancer: a case-control study in Ontario, Canada. Cancer Causes Control 1995;6:145-154.

-49 Tzonou A, Signorello LB, Lagiou P, Wuu J, Trichopoulos D, Trichopoulou A: Diet and cancer of the prostate: a case-control study in Greece. Int J Cancer 1999;80:704-708.

50 Ramon JM, Bou R, Romea S, Alkiza ME, Jacas M, Ribes J, Oromi J: Dietary fat intake and prostate cancer risk: a case-control study in Spain. Cancer Causes Control 2000;11: 679-685.
51 Chavarro JE, Stampfer MJ, Hall MN, Sesso $\mathrm{HD}, \mathrm{Ma} \mathrm{J}$ : A 22-y prospective study of fish intake in relation to prostate cancer incidence and mortality. Am J Clin Nutr 2008; 88:1297-1303.

52 Crowe FL, Key TJ, Appleby PN, Travis RC, Overvad K, Jakobsen MU, Johnsen NF, Tjonneland A, Linseisen J, Rohrmann S, Boeing $\mathrm{H}$, Pischon T, Trichopoulou A, Lagiou $\mathrm{P}$ Trichopoulos D, Sacerdote C, Palli D, Tumino R, Krogh V, Bueno-de-Mesquita HB, Kiemeney LA, Chirlaque MD, Ardanaz E, Sanchez MJ, Larranaga N, Gonzalez CA Quiros JR, Manjer J, Wirfalt E, Stattin P, Hallmans G, Khaw KT, Bingham S, Ferrari P, Slimani N, Jenab M, Riboli E: Dietary fat intake and risk of prostate cancer in the European Prospective Investigation into Cancer and Nutrition. Am J Clin Nutr 2008;87: 1405-1413.

53 Koralek DO, Peters U, Andriole G, Reding D, Kirsh V, Subar A, Schatzkin A, Hayes R, Leitzmann MF: A prospective study of dietary alpha-linolenic acid and the risk of prostate cancer (United States). Cancer Causes Control 2006;17:783-791.

54 Schuurman AG, van den Brandt PA, Dorant E, Goldbohm RA: Animal products, calcium and protein and prostate cancer risk in the Netherlands cohort study. Br J Cancer 1999; 80:1107-1113.

55 Veierod MB, Laake P, Thelle DS: Dietary fat intake and risk of prostate cancer: a prospective study of 25,708 Norwegian men. Int J Cancer 1997;73:634-638.

56 Wallstrom P, Bjartell A, Gullberg B, Olsson $\mathrm{H}$, Wirfalt E: A prospective study on dietary fat and incidence of prostate cancer (Malmo, Sweden). Cancer Causes Control 2007; 18: 1107-1121.

57 Andersson SO, Wolk A, Bergstrom R, Giovannucci E, Lindgren C, Baron J, Adami HO: Energy, nutrient intake and prostate cancer risk: a population-based case-control study in Sweden. Int J Cancer 1996;68:716722 .

58 Kristal AR, Cohen JH, Qu P, Stanford JL: As sociations of energy, fat, calcium, and vitamin D with prostate cancer risk. Cancer Epidemiol Biomarkers Prev 2002;11:719-725.

59 Kolonel LN: Fat, meat, and prostate cancer. Epidemiol Rev 2001;23:72-81.

60 Pham TM, Fujino Y, Kubo T, Ide R, Tokui N, Mizoue T, Ogimoto I, Matsuda S, Yoshimura T: Fish intake and the risk of fatal prostate cancer: findings from a cohort study in Japan. Public Health Nutr 2009;12:609-613.

-61 Bairati I, Meyer F, Fradet Y, Moore L: Dietary fat and advanced prostate cancer. J Urol 1998;159:1271-1275.
62 De Stéfani E, Deneo-Pellegrini H, Boffetta P, Ronco A, Mendilaharsu M: Alpha-linolenic acid and risk of prostate cancer: a case-control study in Uruguay. Cancer Epidemiol Biomarkers Prev 2000;9:335-338.

63 Fradet V, Cheng I, Casey G, Witte JS: Dietary omega-3 fatty acids, cyclooxygenase- 2 genetic variation, and aggressive prostate cancer risk. Clin Cancer Res 2009;15:25592566.

64 Meyer F, Bairati I, Shadmani R, Fradet Y, Moore L: Dietary fat and prostate cancer survival. Cancer Causes Control 1999;10:245251.

65 Cancer Statistics in Japan, 2007.

66 Mozaffarian D, Rimm EB: Fish intake, contaminants, and human health: evaluating the risks and the benefits. JAMA 2006;296: 1885-1899.

67 Brouwer A, Longnecker MP, Birnbaum LS, Cogliano J, Kostyniak P, Moore J, Schantz S, Winneke G: Characterization of potential endocrine-related health effects at low-dose levels of exposure to PCBS. Environ Health Perspect 1999;107(suppl 4):639-649.

68 Ritchie JM, Vial SL, Fuortes LJ, Robertson LW, Guo H, Reedy VE, Smith EM: Comparison of proposed frameworks for grouping polychlorinated biphenyl congener data applied to a case-control pilot study of prostate cancer. Environ Res 2005;98:104-113.

69 Shahedi K, Lindstrom S, Zheng SL, Wiklund F, Adolfsson J, Sun J, Augustsson-Balter K, Chang BL, Adami HO, Liu W, Gronberg H, $\mathrm{Xu}$ J: Genetic variation in the COX-2 gene and the association with prostate cancer risk. Int J Cancer 2006;119:668-672.

70 Cheng I, Liu X, Plummer SJ, Krumroy LM, Casey G, Witte JS: COX2 genetic variation, NSAIDS, and advanced prostate cancer risk. Br J Cancer 2007;97:557-561.

-71 Panguluri RC, Long LO, Chen W, Wang S, Coulibaly A, Ukoli F, Jackson A, Weinrich S, Ahaghotu C, Isaacs W, Kittles RA: COX-2 gene promoter haplotypes and prostate cancer risk. Carcinogenesis 2004;25:961-966.

72 Massaro M, Habib A, Lubrano L, Del Turco S, Lazzerini G, Bourcier T, Weksler BB, De Caterina R: The omega-3 fatty acid docosahexaenoate attenuates endothelial cyclooxygenase-2 induction through both $\mathrm{NADP}(\mathrm{H})$ oxidase and PKC epsilon inhibition. Proc Natl Acad Sci USA 2006;103:15184-15189.

73 Smith WL, DeWitt DL, Garavito RM: Cyclooxygenases: structural, cellular, and molecular biology. Annu Rev Biochem 2000;69:145182. 